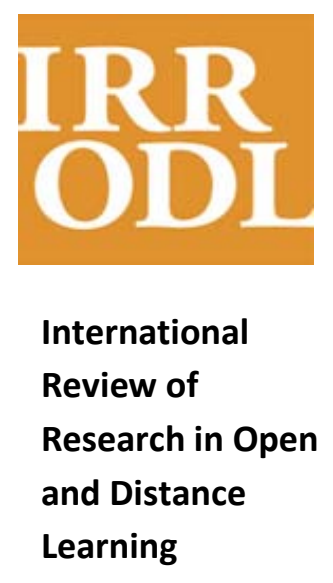

Vol. 12.3

March - 2011

\section{Dialogue and Connectivism: A New Approach to Understanding and Promoting Dialogue-Rich Networked Learning}

\author{
Andrew Ravenscroft \\ Learning Technology Research Institute (LTRI), London \\ Metropolitan University, UK
}

\begin{abstract}
Connectivism offers a theory of learning for the digital age that is usually understood as contrasting with traditional behaviourist, cognitivist, and constructivist approaches. This article will provide an original and significant development of this theory through arguing and demonstrating how it can benefit from social constructivist perspectives and a focus on dialogue. Similarly, I argue that we need to ask whether networked social media is, essentially, a new landscape for dialogue and therefore should be conceived and investigated based on this premise, through considering dialogue as the primary means to develop and exploit connections for learning. A key lever in this argument is the increasingly important requirement for greater criticality on the Internet in relation to our assessment and development of connections with people and resources. The open, participative, and social Web actually requires a greater emphasis on higher order cognitive and social competencies that are realised predominantly through dialogue and discourse. Or, as Siemens (2005) implies in his call to rethink the fundamental precepts of learning, we need to shift our focus to promoting core evaluative skills for flexible learning that will, for example, allow us to actuate the knowledge we need at the point that we need it. A corollary of this is the need to reorient educational experiences to ensure that we develop in our learners the ability "to think, reason, and analyse." In considering how we can achieve these aims this article will review the principles of connectivism from a dialogue perspective; propose some social constructivist approaches based on dialectic and dialogic dimensions of dialogue, which can act as levers in realising connectivist learning dialogue; demonstrate how dialogue games can link the discussed theories to the design and performance of networked dialogue processes; and consider the broader implications of this work for designing and delivering sociotechnical learning.
\end{abstract}

Keywords: Theory; dialogue; design; networked learning; pedagogy; dialogue games; computer mediated communication 


\section{Introduction: Connectivism and Learning in the Digital Age}

The relatively recent theoretical accounts of connectivism (Siemens, 2005, 2006) and connective knowledge (Downes, 2006) as ways to understand and explore learning in the networked digital age are timely and particularly useful, both in what they offer and what they question. These positions are not without their critics, Verhagen (2006) for example, but what is particularly exciting and important about them is that they have started a serious discourse, and hopefully discipline-wide reflection, about what learning is in the digital age, the inescapable and unavoidable role of networked technologies as mediating artifacts for learning, and how we should design and support learning for the digitally literate learner in the networked landscape. These approaches foreground the role of network technologies, the connections within these networks, and how these influence an evolving and relative perspective on knowledge. Interestingly, until now, these emphases have not considered the role of dialogue. However, dialogue is the primary mechanism for maintaining connections and developing knowledge through them. This suggests a pivotal role for dialogue interaction in meaning making and learning within networks and similar open enterprises, such as personal learning environments (Attwell, 2007) or the Web in general. In reflecting upon this state of affairs this article addresses the following question: Is networked social media ostensibly a new and profound dialogue landscape and therefore should it be investigated in these terms? In certain ways I extend some initial thoughts, justifications, and directions that have been proposed by Siemens (2005, 2006) and Downes (2006), but take these a step further through a deliberate focus on digital dialogue as a lens through which we can better understand connectivism and design future networked learning that embraces its potentials.

Siemens (2005) states the following principles of connectivism, which are also currently available through Siemens' writings in Wikipedia.

1. Learning and knowledge rest in diversity of opinions.

2. Learning is a process of connecting specialised nodes or information sources.

3. Learning may reside in non-human appliances.

4. Capacity to know more is more critical than what is currently known.

5. Nurturing and maintaining connections is needed to facilitate continual learning.

6. Ability to see connections between fields, ideas, and concepts is a core skill.

7. Currency (accurate, up-to-date knowledge) is the intent of all connectivist learning activities.

8. Decision making is itself a learning process. Choosing what to learn and the meaning of incoming information is seen through the lens of a shifting reality. While there is a right answer now, it may be wrong tomorrow due to alterations in the information climate affecting the decision. 
Below, we consider these from a digital dialogue perspective that in some ways is in harmony with Downes' (2006) position that

These trends combine to form what is sometimes called "elearning 2.0" - an approach to learning that is based on conversation and interaction, on sharing, creation and participation, on learning not as a separate activity, but rather, as embedded in meaningful activity such as games and workflows.

But, in accepting this emphasis on "conversation and interaction,” I argue that we need to drill down a level deeper as these are very wide-ranging and somewhat diffuse concepts. I hold that for learning we also need to ask the following: What sort of dialogue features, forms, or genres are implicated in the realisation of these principles and therefore will support networked learning?

\section{Are New Dialogues the Most Prominent Feature of a Networked Social Media Landscape?}

If we consider the operationalisation of these connectivist principles from a dialogue perspective we find that they frequently implicate ongoing evaluative processes as having prominence over prestructured and content-centric features of dialogue. So, for example, processes such as critical inquiry, reflection, and negotiation are considered more important than informing about or acquiring static knowledge. Specifically, referring to the particular principles, referred to in brackets where appropriate in the following sections, we can say the following. Diverse opinions (1) will be typically expressed through discourses and clarified, contested, and refined through critical dialogue. The connection of specialised and contextualised information sources (2) will involve the assessment of discourses, reflections about them, and recognition of meaning and value. The principle that "Learning may reside in non-human appliances" (3) seems to play out in two ways from a dialogue perspective, although the word "reside" perhaps needs additional qualification. Firstly, some types of intelligent applications, such as those that include machine learning, user modeling, or semantic techniques, typically learn, or colearn, with humans. Other technologies that don't necessarily learn themselves but are explicitly designed to promote learning in humans, such as intelligent tutors and learning simulations or games, can be said to have the capacity for learning within them. To realise a capacity to know more (4) will benefit from reflective and inquiry dialogue to maintain and evolve a community of inquiry and function critically within these spaces. Similarly, nurturing and maintaining connections (5) with people can correspond to opening up and maintaining what Wegerif (2007) calls "dialogic spaces" that emphasise "the interanimation of real voices" within learning relationships. These may then support learning through dialectical and knowledge-building dialogues of the type proposed by Scardamalia and Bereiter (2003). "Seeing connections" (6) is likely to involve dialogue processes such as reflection, clarification, and negotiation. And currency (7) will be realised through maintaining up-to-date and responsive dialogues, and we will often decide what to learn (8) through processes such as clarifying, reflective engagement, and negotiation. 
I will now elaborate further on this dialogue lens based on some of the central precepts of connectivism that aren't explicitly stated in these principles but have been emphasised elsewhere by Siemens (2005, 2006). Thinking in networks will usually mean thinking through collaborative dialogue. Most meaningful learning and active engagement will be realised and maintained by similarly meaningful dialogue processes. We will often perform sense making through continuous discourses that coconstruct and negotiate meaning. Language and dialogue are the key underpinnings of social behaviour and learning. It is virtually impossible to imagine social processes that are divorced from dialogue processes. Also, the notion that sociality is constantly created and recreated maps to the emergence and evolution of dialogic spaces that support the development of relationships and the coordination of joint activities. Along these lines it is important to remember that our networked social behaviour did not begin with social media, but is instead coevolving with these technologies, which arguably provide social opportunities that are more open, and are used more often, than was previously possible with the traditional methods of communication, dialogue, and discourse.

Summarising, the operationalisation of these principles of connectivism seems closely interwoven with ways to characterise the richness of the evolving dialogue processes linked to new digital technologies and practices. Three related questions in this respect, which are the platform for the original contribution of this article, are

1. How can we better understand the dialogue processes that are implicated by connectivist learning in a networked world?

2. What are the dialogue features of quality connections for networked learning?

3. How do we, through design, promote and catalyse the development and operation of quality connections?

In addressing these questions it is also useful to consider that although the form and means of realisation of learning dialogue are changing through the increased prevalence of highly participative and discourse-intensive social software, or Web 2.0 technologies, some underpinning pragmatic level, or deep and social, discourse processes are arguably more stable and still at play. For example, we will always use dialogue, as our most intuitive semiotic system, to articulate and express what we think, share our thoughts and ideas with others, and collaboratively create meaning and understanding to make joint inquiries or to solve common problems. We may be performing these practices in more immediate, participative, or multimodal ways, but the deep psycho-social imperatives are more impervious to change and will benefit from a deeper understanding of social constructivist ideas that emphasise the primacy of dialogue in learning. In showing this I will explore and extend a recent way to characterise and understand digital learning dialogue that was proposed by Ravenscroft, Wegerif, and Hartley (2007), based on exploring Vygotskian dialectic and Bahktinian dialogic ideas, before considering how these can be incorporated within a dialogue-rich and connectivist approach to learning and its design. 


\section{Elaborating the Dialogue Perspective: Social Constructivist Theoretical Levers}

The following section considers a Vygotskian and dialectic account of learning dialogue, followed by a Bahktinian and dialogic account, before synthesising both within the frame of contemporary contexts for connectivist learning. This section restates and extends the previous work that was reported in Ravenscroft, Wegerif, and Hartley (2007) and Ravenscroft, Sagar, Baur, and Oriogun (2009).

This theoretical exploration is interesting because at an initial level of analysis social constructivism and connectivism are quite different. The former foregrounds the psychology of human development from a sociocultural perspective that includes interpersonal processes that lead to the development of higher mental processes. One primary way in which this is engineered is through setting up and participating in a zone of proximal development (ZPD) that connects a learner with a more learned other (Vygotsky, 1978). It also highlights the primacy of language and dialogue within this process, where the internalization of external dialogue processes leading to the formation of internal psychic tools that support reasoning, reflection, and the development of higher mental processes is central. And, not surprisingly, given that this theory was developed in the early twentieth century, there is no consideration of how dialogue-rich information technology influences this process. But this is precisely where there is a harmonious join because connectivism, with its deliberate focus on the here-and-now reality of how digital networks support new forms of connections, social relations, and dialogue, provides a sociotechnical frame or set of creative constraints within which contemporary social constructivist activities occur. The sections below elaborate on this through further refining social constructivism into dialectic and dialogic before showing how these processes can be structured by connectivist constraints within networked learning contexts through dialogue games that are mediated by a tool called InterLoc (Ravenscroft, McAlister, \& Sagar, in press ).

\section{Dialectic, Learning, and Connectivism}

In considering dialectic dialogue processes, Ravenscroft, Wegerif, and Hartley (2007) argued the following:

The dialectic that was used by Socrates (470-399 BC) during what has become known as "the Socratic method" is one of the earliest recorded educational approaches. This has remained an inspiration to contemporary approaches to learning, such as computer-based tutorial learning proposed by Bork (2001), that he offers as the most important learning model for the twentyfirst century. The essence of the method is that through careful questioning by the teacher, students can come to realize the truth of a situation without being told it directly. For Socrates argument and learning was embedded in these real dialogues. 
Hegel (1770-1831) turned dialectic into a more abstract notion of a dynamic logic proceeding from thesis to antithesis and then synthesis. Hegel's (1975) approach rested on a coherence theory of truth, where the truth relies not on a single proposition but a whole system of propositions, and only within this complete system can contradictions be recognised and falsity removed. Similarly, the process of synthesis preserves the rational and removes the irrational but then also provides another thesis that can become the subject of the same triadic process, and so on. So for Hegel, although "The true is the whole", this is an evolving whole that develops through contradiction. (p. 40)

Through applying Hegel's dialectic Marx argued that culture and consciousness arise as tools in the dialectic interaction between humans and nature. Vygotsky took this as a model of how an individual consciousness is formed through the internalisation of tools. So Vygotsky's (1978) theory of the development of higher mental processes can remain a foundation and inspiration for approaches to networked technology enhanced learning (hereafter TEL) that emphasise collaborative, argumentative, and reflective discourses, along the lines that have been emphasised by Mercer (2000), Ravenscroft (2000, 2004) and Wertsch (1991).

This dialectic position maps to connectivism in a number of significant and related ways that are given below where essentially these mappings concur with how to deal with a new "provisionality" associated with twenty-first-century knowledge practices. In adding to these accounts above, we now also need to take full account of the mediational power offered by new and evolving digital tools, which is another anchor in connectivist thinking.

The mappings are mostly related to the energetic process and form of dialogue. Firstly, dialectic is a suitable process for refining knowledge and realising learning from a diversity of opinions (1), and similarly, supporting the capacity to always know more (4). Secondly, implicit in dialectic processes is the ability to foreground and emphasise new connections (6) through the consideration of new or alternative positions and viewpoints of others. Thirdly, the way in which dialectic implies this constant evolution of knowledge, for example through the Hegelian triadic process, should foster currency (7). Fourthly, the decisions about what to learn in a shifting reality (8) can be optimized through ongoing and frequent critical and collaborative dialogue. In brief, the constructive criticality, combined with the energy and edge of dialectic dialogue processes, can act as an engine for connectivist and networked learning.

\section{Dialogic, Learning, and Connectivism}

In considering dialogic dialogue processes, Ravenscroft, Wegerif, and Hartley (2007) argued the following:

Bakhtin (1986), a contempory of Vygotsky, went back to the

Greeks to argue that dialectic had become over formalized and 
we needed to return to real dialogues. He said dialectic is a dynamic form of logic leading all apparent differences to be subsumed into identity in the form of a more complexly integrated synthesis. Bakhtin argued that logic itself has no meaning, it is only the clash of different voices that gives meaning. He opposed what he called 'Hegel's monological dialectic' with his notion of dialogic that referred to the interanimation of real voices where there is no necessary 'overcoming' or 'synthesis' (Wegerif, 1999). Following Wertsch (1991) the sociocultural approach has tended not to recognize this and instead has combined together two notions of mediation, Vygotskys account of mediation by tools including words as sign-tools (dialectic) and Bakhtin's account of mediation by the voices and perspectives of others (dialogic). While mediation by tools is not incompatible with mediation by the perspective of the other person and both happen in education, it is important to point out that these are very different kinds of mediation, which can be conceived as different dimensions, or features, of the dialogue process. For each participant in a dialogue, the voice of the other is an outside perspective that includes them within it. The boundary between subjects is not therefore a demarcation line, or an external link between self and other, but an inclusive 'space' within which self and other mutually construct and reconstruct each other. (pp. 43-44)

Wegerif (2007) has argued very strongly for this dialogic approach to learning, where he considers that the main mechanism for learning is taking the perspective of another in a dialogue, where the dialogue is an end to be valued in itself as perhaps the most important goal of education. Recently, Wegerif (2007) has argued powerfully for this perspective to "expand the spaces of learning" through digital technologies and emphasised that it's not just the use of explicit reasoning but the ability to change one's mind and see things from a new perspective that is essential for learning. So, as with dialectic, there is the clear call to foreground the proactive role of social technologies in networked learning.

This dialogic position also maps to connectivism and networked learning in a number of significant ways, related to the conditions, context, and intersubjective orientations (Bahktin, 1986) that are appropriate for cothinking and learning. Firstly, it embraces the diversity of opinions (1) whilst recognising that these will not necessarily be, or need to be, resolved through logic. Instead it holds that the capacity to keep real, collaborative, and meaningful dialogue "in play" and learn through genuinely considering the perspective of others within inclusive spaces (2) is arguably more important than being driven by an undercurrent logic. Secondly, implicit in this perspective is the capacity to always know more (4) as operating in a dialogic space means that we will be constantly exposed to new or conflicting ideas that we are encouraged to explore and understand, rather than reject or attack in favour of preexisting personal beliefs or ideas. 
Thirdly, cultivating and maintaining these dialogic spaces corresponds to nurturing and maintaining connections that facilitate learning (5). Fourthly, if learners operate in this dialogic way in learning networks they will inevitably be open to seeing and understanding new connections (6) and staying up to date through being in continual learning relationships (7), as well as having the opportunity to make decisions (8) about what it is they want to learn or think is important and relevant to learn.

\section{Dialectic or Dialogic? Relative Dimensions for Networked Learning Dialogue}

The relationship between these two characterisations of dialogue, and the implications for learning, was also explored by Ravenscroft, Wegerif, and Hartley (2007). A key question they asked was whether these two characterisations, or genres, worked together or in opposition. Previous work of Ravenscroft and his colleagues in designing dialogue games for conceptual change in science (e.g., Ravenscroft \& Pilkington, 2000; Ravenscroft \& Matheson, 2002) has shown that an argumentative and dialectical approach was needed for a student and tutor to achieve a synthesis around a correct conceptual understanding of the physics of motion. In contrast, Wegerif (2007) has argued and demonstrated that in some circumstances, especially when dealing with younger children and those with emotional and behavioural problems, a dialogic approach, with its emphasis on "taking the perspective of another," is more important than progression towards some sort of synthesis around a common understanding. So considering their previous work collectively, they argued that dialectic and dialogic are two relative dimensions that are not in opposition as they focus on different yet equally important features of the dialogue process relevant to learning. Dialectic emphasises the epistemic and cognitive dimensions of learning that can be realised through identifiable forms of dialogue processes that occur when an appropriate dialogic state is established. Dialogic emphasises emotional and interpersonal dimensions or the sorts of "relationships" and "intersubjective orientations" (Habermas, 1991) that enable the spaces where learning can happen. These represent a complementary emphasis, which Ravenscroft, Wegerif, and Hartley summed up by saying:

The desire to reason to progress towards a rational synthesis does not have to override the need to understand others, and likewise, the desire to understand others does not have to override the often pragmatic need to reach a rational consensus that links to purposeful action in a context. The two will always interplay and vary in emphasis based on what is wanted from a learning situation. (2007, p. 46)

And to further emphasise these points, they held that this position paraphrased the thinking of Kant:

dialectic without dialogic is blind (as in machine cognition), dialogic relations without dialectic is empty of content (as in the 
mother child couple): it is through their union that new shared understandings can arise. (p. 47)

So in terms of contributing to our understanding and realisation of connectivist dialogues in learning networks, both of these perspectives are, arguably, equally valuable. And similarly, we may need both approaches to operate in a complementary way if we want "real" learning to occur. Whereas dialectic is an engine that can energise and shape the form and process for connectivist and networked learning, dialogic is the sophisticated housing structure which sets up the appropriate relationships, epistemological orientations, and general conditions for learning to take place.

\section{Connectivism and Contemporary Contexts for Learning}

Further parallels with key aspects of connectivism related to dialectic and dialogic were also made in a later article by Ravenscroft et al. (2009), who said,

... through social and more open technologies we are creating new spaces and contexts which have the potential for dialectic and dialogic learning through new and developing digital literacies. These contexts can often be conceived 'democratic spaces' that are either generated or populated by the users, whose relationships mediate learning as much as the processes and tools that are in play. These contexts are clearly creating new forms of intersubjective orientations where learning can happen, that are shaped through open participation, collaboration, multimodal language, the provisionality of representations and could potentially contribute, generally, to a more "democratic epistemology.” (p. 418)

These researchers also drew together these interconnected notions about connectivism, dialogue, and collaborative thinking by comparing it to a key proposition proposed by Friere (2001), who said,

To think correctly implies the existence of subjects whose thinking is mediated by objects that provoke and modify the thinking subject. Thinking correctly is, in other words, not an isolated act or something to draw in isolation but an act of communication... For this reason, a correct way of thinking is dialogical not polemical. (pp. 42-43)

This articulation aligns well with Siemens' notion of "thinking in networks," but adds an additional dialogue dimension related to the idea that communication and cognition are actually inseparable and essentially part of a greater social imperative. This also aligns with the point 
made by Ravenscroft (2004) in a critique of a pure community of practice (CoP) approach to learning:

When we consider the pedigree and support for socio-cognitive approaches . . . we cannot accept the claim that "Learning is a process that takes place within a participation framework, not an individual mind" without significant qualification. Surely, learning is a process that takes place within a participation framework and an individual mind. (p. 8)

This position is further strengthened if we don't ask where does the knowledge lie and instead ask how is knowledge beneficially refined, developed, and transformed through technology-mediated practices? This allows us to escape the possibly false dichotomies between individual cognition, distributed cognition, individual learning, and networked learning, etc. as we will always learn by being alone and together.

In embracing these new networked and highly social contexts and possibilities, this position also aligns with what tends to be called "egalitarian dialogue," which foregrounds the assessment of contributions in terms of the validity of the arguments presented rather than according to any power positions of those who advocate them.

I argue that all the perspectives, or levels, for understanding the dialogue process that are discussed above are important for connectivist and networked learning. Thus far, a lot of research has focused on the connection-forming potentials and propensities provided by open and social technologies that build upon network theory and the Internet architecture. This article provides an additional, original, and nuanced perspective on this theoretical and practical situation that looks at the prospects for greater understanding and better design of the learning dialogue processes that operate over social networks.

\section{Tools, Dialogue Genres, Knowledge Building, and Networked Learning}

What do the ways to better understand digital dialogue that I have argued for above contribute to more directly designing and promoting networked learning and the related and well-founded approach of knowledge building as it is defined by Scardamalia and Bereiter (2003)? Three related implications are that understanding these ideas should allow us to consider the nature and form, or genre, of desired dialogue processes and better problematize a learning and knowledgebuilding situation; enable the selection or combination of tools that will optimally mediate practices that address our learning and knowledge-building ambitions and requirements within given contexts; and, where existing tools are not available, be a foundation for tool design. Too often in practice these aims are erroneously conflated, producing mismatches between the affordances of tools and the educational expectations of them in learning situations. The TEL literature, or research that doesn't make it to literature, is replete with examples of this. Herring (1999) and McAlister, Ravenscroft, and Scanlon (2004) clearly showed the shortcomings of instant messaging and chat in supporting reasoned discussion that could lead to knowledge 
building, and a recent journal special issue on "Social Software, Web 2.0 and Learning" (Ravenscroft, 2009) showed that attempted social media learning solutions often did not harmonise with or understand the actual learning-teaching problem they were meant to address. In applying this argument I now introduce a theory-driven approach to design that addresses the specific problem of promoting critical thinking and reasoned dialogue to support knowledge building on the Internet. This research arose out of the UK Open University, which, after considerable efforts to exploit synchronous chat and asynchronous forums for critical discourse amongst distance learners, realised that it needed to explicitly design for critical discussion, reasoning, and related knowledge building rather than expecting it would occur. This was achieved through research incorporating an anatomy (or ontology) and explicit process for collaborative argumentation, derived from the dialectic and dialogic ideas that were proposed above. Note that this approach does not override using other dialogue technologies where they are more appropriate. Put simply, I would propose using chat or microblogging to hold immediate informational exchanges, conferencing and blogging for reflective commenting, and digital dialogue games for "live” and collaborative thinking and knowledge building on the Internet.

\section{Dialogue Games: From Theory to Designing for Dialogue Processes}

Whilst the theoretical work above helps us to better understand connectivist and networked learning dialogue, if we want to ensure that we promote it we need additional concepts that directly link theoretically informed accounts to the design of dialogue-rich learning applications and experiences. One such theoretically strong design concept is dialogue games that incorporate other design-oriented theories such as speech acts (Searle, 1969).

Dialogue games are a well-established paradigm for designing learning dialogue (e.g., Ravenscroft, 2007) and argumentative dialogue in general (e.g., Moore, Yuan, Reed, Ravenscroft, \& Maudat, 2009) that synthesise work from the philosophy of language (e.g., Wittgenstein, 1953; Mackenzie, 1979; Walton, 1984), computational linguistics (e.g., Levin \& Moore, 1977), and design-based studies of learning dialogue (see Ravenscroft, 2007 for a review). The latter approach is driven by the Vygotskyan and Bahktinian notions that have informed the contemporary articulation of dialectic and dialogic dimensions of learning dialogue that were mapped to the connectivist principles and given above. This work has been reported extensively in previous articles, which cover the applied design based research approach of deep learning design (Ravenscroft \& Boyle, 2010), the history of the development of the dialogue game framework (see Ravenscroft, 2007 for a review) and the methodological approaches and findings related to the evaluation of the games and the tools that realize them (Ravenscroft \& McAlister, 2008). Some relevant parts from Ravenscroft, McAlister, and Sagar (in press) are restated and extended below. This dialogue game work has recently been complemented and realised through applying new design-oriented and conceptual principles of "ambient pedagogy" and "experience design” (Ravenscroft et al., 2009) to adapt the dialogue game approach directly to the social media landscape. In succinct terms, ambient pedagogy holds that the structure or scaffolding supporting the learning interaction is behind the scenes and yet also implicit in the digital practice that is supported; and "experience design" emphasises that the learning occurs through the production of an experiential context and ecosystem, or space that favours learning, in contrast to 
foregrounding the management of instruction and explicit pedagogical design. This elaborated dialogue game approach is used to address relatively generic learning problems and opportunities related to the need for critical and reasoned dialogue, often linked to thoughtful writing. It has recently been deployed through the InterLoc tool and evaluated across five UK higher education institutions with over 350 students and 10 tutors (Ravenscroft, McAlister, \& Sagar, in press). The results of these evaluations showed that the approach was highly valued by tutors and students, was effective in promoting critical thinking and reasoned discourse, and generally supported much deeper engagement between peers than is typical with other dialogue technologies.

Essentially, these social games realise engaging and structured rule-based interactions within networked spaces, which are performed using predefined dialogue features (such as dialogue moves, locution openers and a model of turn taking) that are specifically designed to foster thinking and learning in ways that are popular with learners (Ravenscroft, McAlister, \& Sagar, in press). All contributions or replies are made using move categories (inform, question, challenge, etc.) and further scaffolded through using specific locution openers (I think . . ., I disagree because ...., Let me elaborate ... etc.) that have to be used to perform the dialogue. Similarly, rules about the legitimate and logical responding openers, based on the specific openers that are replied to, are offered selectively, but these can be overridden where necessary. The model of turn taking is incorporated to ensure that the dialogues support "listening" to others' contributions, fairly balanced patterns of contribution, and, generally, the sort of coherent sequencing that results in reasoned discourses.

A key point about these dialogue games realised through InterLoc is that all the features above are easily configurable, so dialogue moves, locution openers, and rules of interaction can be selected or developed to promote ostensibly dialectical dialogue processes, dialogic dialogue, or complementary combinations of both. The latter has been found to be the most popular and effective configuration within a game called the Critical Discussion and Reasoning Dialogue Game (CDR-DG). The following section demonstrates how this dialogue game realises these dialectic and dialogic processes that correspond to connectivist networked learning and other key aspects of connectivism.

\section{Networked Learning Dialogues through InterLoc: Realising Connectivist, Dialogic, and Dialectic Dimensions}

This section provides a concise account of how the dialogue games and InterLoc operate for the purposes of this paper, with its focus on the theory and application of connectivism and dialoguerich networked learning. A more comprehensive and detailed account is given in Ravenscroft, McAlister, and Sagar (in press).

Practically speaking, the current dialogue game technology, InterLoc5 (Ravenscroft, McAlister, \& Sagar, in press), embodies the pressing need to reconcile learners and knowledge workers developing digital literacies and practices with the well-established requirements for reasoned and purposeful learning dialogues, such as those supporting critical and creative thinking. It realises social games that are performed amongst small groups of four to six players that can be easily 
scaled and replicated across many simultaneous groups. Through orchestrating interaction and learning through dialogue games we can connect anyone who can access the Web and include any resources that are available on the Internet.

The texts that result (see Figure 1) are more formal than records of unstructured chat or dialogue that is typical in conferencing software, and yet are less formal - in terms of textual representation - than a typical wiki or blog.

These types of digital dialogue records are significant in that they capture "live collaborative thinking.” These can provide unique intermediary representations between collaborative thinking and thoughtful writing. In a sense, the current dialogue game approach is a way of generating and capturing thinking on the Web in ways that realise and satisfy accepted ambitions for learning that also sits with more informal and media-driven digital practices with social software.

\section{Playing the Dialogue Game}

The interface in Figure 1 shows how each player performs the dialogue game. This was taken from an exercise performed by postgraduate students at a UK university who were critically discussing the National Curriculum (or NC) for Science (which is also reported in more detail in Ravenscroft, McAlister, and Sagar, in press). They can contribute to the current state of the developing dialogue through selecting either "contribute" or "reply" to a specific previous contribution. "Contributing" to the dialogue places a message at the bottom of the display while "reply" indents responses below the specific contribution that is replied to (preserving a thread). This model contains affordances that achieve a balance of "keeping the dialogue moving forward" whilst allowing reflective asides and specific responses to previous contributions. So players need to distinguish whether they are "contributing" to the developing dialogue (using the large reply bar at the bottom), typically responding to the latest state of the dialogue or replying to a specific previous contribution (by selecting "reply" next to each contribution). All contributions or replies are made using the predefined move categories (inform, question, challenge, etc.) and the specific locution openers (I think ...., I disagree because ..., Let me elaborate . . . etc.). Similarly, rules about the legitimate and logical responding openers, based on the specific openers that are replied to are offered selectively. So in this example (in Figure 1) the responding player (george) is presented with logically legitimate responses to I disagree because ..., such as Is there another way of looking at it?, Why do you think that?, etc., although he is not restricted to this preferred response set and can instead select More to see the full range of openers. So a structured and yet flexible form of scaffolding is provided.

This brief excerpt, and the context in which it was conducted, is able to demonstrate the harmonisation of dialogic and dialectic features along connectivist lines and also highlight some of the key principles of connectivism.

Beginning with the principles, firstly, the rationale behind dialogue games and InterLoc is that people learn and collectively advance knowledge and understanding through argument and critical inquiry. Implicit in this approach is an acceptance that diversity of opinion (1) is the 
"intercognitive engine” that drives the argumentation process. Secondly, the learning design that InterLoc realizes deliberately connects particular people and particular resources, which are the "specialised nodes or information sources" (2). The design of the dialogue games and InterLoc, which comprise a "non-human appliance," ensures that collaborative argumentation occurs in ways that correspond to learning (3) and the collaborative development of understanding. Also implicit in the dialogue game rationale is that, through legitimate and continued argument, we can continually develop and improve our understanding of a domain, which maps to the principle that it is more important and critical to know more than is currently known (4). Principles 5, 7, and 8 are less evident in InterLoc's design and practices. But also central to dialogue games is that, through inquiry style interchanges, we have a greater ability to see and confirm connections between ideas and concepts (6), and also to qualify and refine the semantics of these connections and relations through more critical and argumentative exchanges.

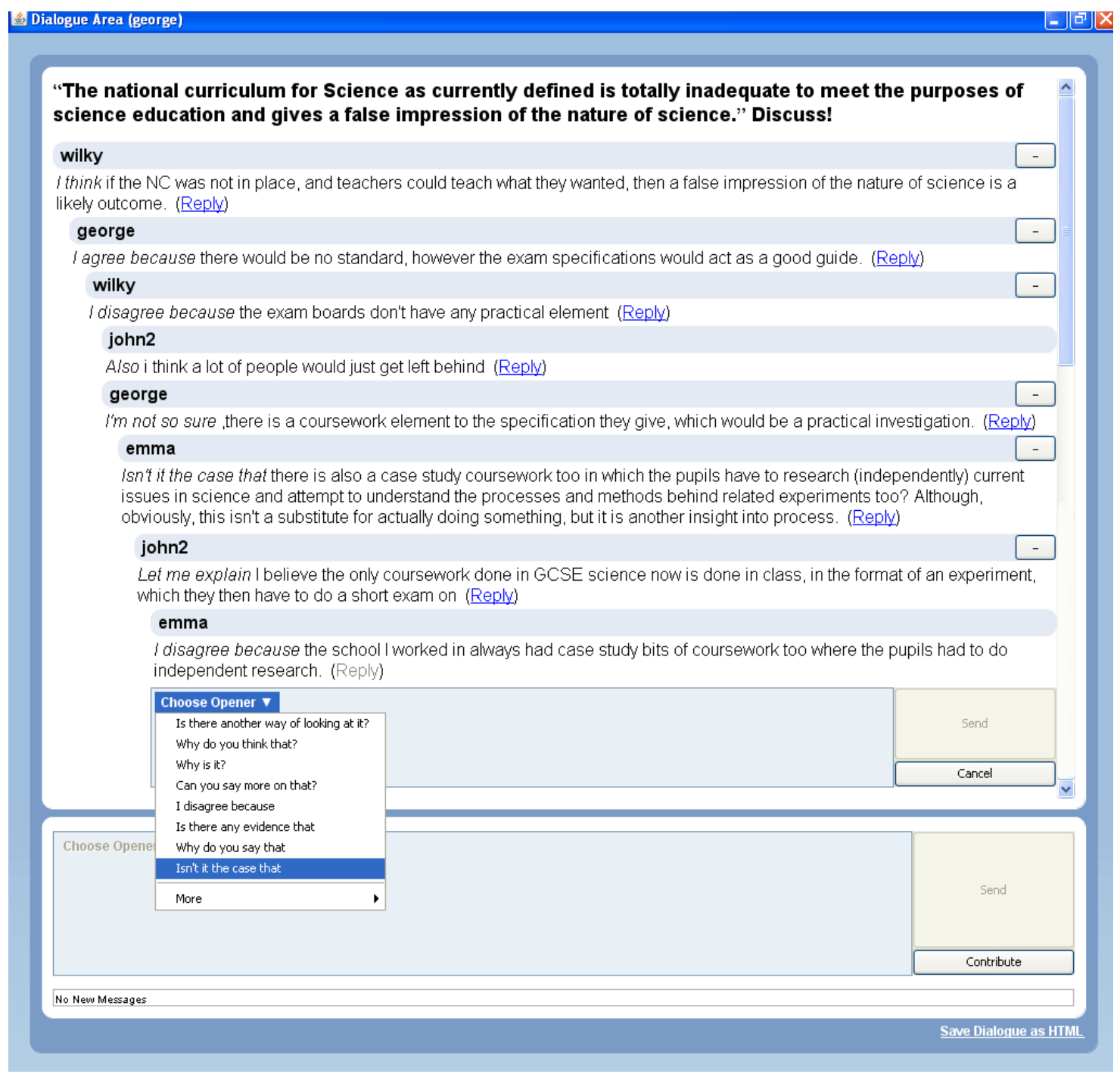

Figure 1. A critical dialogue demonstrating how connectivist, dialectic, and dialogic features are realised through InterLoc. 
If we now focus on how dialectic and dialogic dimensions harmonise with connectivism more generally, firstly, the setting of an open question (bolded at the top of the screen), with a number of potential positions, within a collaborative "group space” where all players share the symmetric role (of player) and the same dialogue features - creates a dialogic space. This sources and stimulates collaborative inquiry and argument and a readiness to colearn what is not yet known. Similarly, this sort of connected learning experience could not be realised without the design of this nuanced network technology (InterLoc) to mediate the colearning amongst the participants deliberately through exploring, challenging, and reconciling diverse and differing opinions.

In turning our attention to the openers that are used and offered in the screenshot of this interface we can see this balance of dialogic and dialectic dimensions. Although I fully accept that the subtleties of interpretation will be dictated through the play of dialogue over series of interchanges within a particular context, following Wittgensteinian (1953) notions of "meaning as use," this level of analysis below helps to explain my position for the purpose of this paper. Replying to another's assertion (about the adequacy of the National Curriculum in the UK) with $I$ agree because ...., Also ... ., Can you say more on that . . represents a mostly dialogic interchange; whereas, responding to the same or similar assertion with I disagree because . .., Is there any evidence that ..., Why is it ... represents a challenging and dialectic interchange. Also, some openers are probably at the borderline of dialogic and dialectic, somewhere between requests for elaboration and challenges. These are openers such as Isn't it the case that ..., I'm not so sure ..., Is there another way of looking at it . .., etc.

As Ravenscroft, McAlister, and Sagar (in press) point out, in this relatively brief interchange we can see how InterLoc supported reasoned agreement, reasoned disagreement, and then the further elaboration and clarification of concepts (related to the role or practical work in the National Curriculum). Summarising the shown conversation, where the individuals have been anonymised through being given "dummy" names, wilky initiates it using an assertion move, I think . ., to offer a position for the role of the NC, to guide (or deliberately restrict) what can be taught about the nature of science - a position that george agrees with, using I agree because . . . . However, wilky then challenges george, using I disagree because ..., to point out that examination boards don’t actually have a "practical element," and john2 points out, using Also . .., to make a related point that otherwise people would get left behind. This introduction of the notion of a "practical element" stimulates george, who uses I'm not sure . .., to point out that maybe there is a practical element in the form of coursework. This then stimulates emma to offer a qualifying question, in the form of Isn't it the case that ..., to offer a more sophisticated position that includes notions of independent study and how this relates to experimental work. This, in turn, stimulates john2 to clarify his position, using Let me explain ... . But emma then challenges john2's clarified position, using I disagree because . . ., to offer a different relationship between coursework and independent study. And finally, this excerpt ends with george about to offer a further qualifying question through selecting Isn't it the case that .... 
So even this brief excerpt, taken from an authentic implementation, demonstrates

- the sort of question (bolded at the top of screen in Figure 1) that seeds the dialogue game and fosters a dialogic space;

- how four participants all contribute to the dialogue, exploring and reconciling different opinions, to perform a well-balanced critical inquiry;

- A good range of moves and openers, including assertions (I think, I agree because, also, let me explain), challenges (I disagree because), and a question (Isn't it the case that?) being used to perform a dialogic and dialectic dialogue;

- how the dialogue game allows the players to quickly identify, consider the importance of, and elaborate their understanding of a key concept, the role of practical or experimental work; and

- how each participant, at this stage of the game, is articulating his or her own and different understanding of how this concept (of practical or experimental work) connects and relates to other aspects of coursework and independent research.

This conversation then goes on to appreciate how the NC is actually open to interpretation in these respects and that coursework now has to consider issues such as plagiarism.

The Digital Dialogue Game Project Evaluation Report (at www.interloc.org.uk) and a number of previous papers (McAlister, Ravenscroft, \& Scanlon, 2004; Ravenscroft \& McAlister, 2006) give a considerable number of longer and more varied dialogue game interactions along with their analysis and evaluation, including comparisons with equivalent chat exercises (Ravenscroft \& McAlister, 2008). The extract used here is deliberately straightforward and illustrative for the purposes of this paper, but it still provides insights about what the dialogue game approach gives us as without InterLoc these sort of networked dialogues are likely to be less well balanced (with some individuals dominating), less deep and detailed, open to more misunderstandings, and generally more poorly reasoned, involving the simple trading of opinions instead of reasoned engagement. Note also that the way in which the openers and interaction design afford participation means that we rarely experience some participants being overly silent during the games (Ravenscroft, McAlister, \& Sagar, in press).

\section{Future Connectivist Dialogues: Reconciling Openness and Orchestration}

One of the reasons why this dialogue game and InterLoc approach works well (Ravenscroft, McAlister and Sagar, in press) is that it has a practical balance of orchestration and openness. And this raises questions about how, or whether, we can move to a more open paradigm. With the current design, a learning manager role (usually a tutor) typically selects the opening question, related resources, and type of dialogue game and also schedules a synchronous interaction and decides whether or how to assess the outcome. So what if we wanted to further personalise and open up this experience through making the role of the tutor or learning manager either optional or unnecessary? Recent work has done this (see Ravenscroft, Braun and Nelkner, 2010; Ravenscroft et al. 2011) and produced a variation of InterLoc that was loosely coupled with a 
social bookmarking and collaborative ontology tool (SOBOLEO) as part of a large-scale European project called MATURE. This supports more responsive and asynchronous dialogue interaction. In this situation the players proposed the question or topic and announce the dialogue game, which can then be joined by anyone in a registered community of practice (CoP). So far, this application has undergone a small-scale formative evaluation that has suggested ways to realise engaging and reasoned dialogues that are also commensurate with the expectations for personal learning environments (PLEs). The central idea is to make the need and means for orchestration explicit, and yet put this under greater learner control. To do this, future developments will realise more visible and open orchestration through tagging resources with dialogue game "invites," semantically processing interactions to identify and propose suitable interlocutors, and generally, linking the dialogue games to related digital learning activities. The latter could be design activities that naturally afford critical and creative discussion amongst groups who are collectively creating a shared artifact. Similarly, future developments will more clearly signal and manage expectations, so users are aware that dialogue games are deliberately reflective and their duration is relatively long term (e.g., from thirty minutes to an hour) and require concentration when compared with instant messaging or microblogging, for example. In other words, we need to accept that thinking and learning together in reflective and reasoned ways requires a commitment that is commensurate with the ambitions for this sort of interaction.

Bearing these experiences in mind, it is important to understand that although social networked systems might be emergent and self-regulating, some form of coordination or orchestration is usually required to support the sort of meaning making that corresponds to learning. To support continual learning requires some level of control of the sort of sense making and meaning making that Siemens (2006) refers to, which can arguably be achieved through reproducible dialogue patterns that catalyse certain learning processes. The implication of this is that we can "design" dialogues to favour certain types of discourse over others, where in our case we want to favour those that are most likely to lead to critical learning within networked and open spaces.

\section{Conclusions}

This article has proposed an original development of theory for networked learning through questioning and elaborating connectivism based on social constructivist thinking and an emphasis on dialogue. It has also argued why this is important and proposed how a "dialogue-rich view" of connectivism can be applied to the design and use of networked learning tools, and demonstrated this through one particular tool called InterLoc. Embracing connectivism means that we need to consider new design metaphors for future learning that place the person, their social behaviour, and their community at the centre of the design process and the resulting networked technologies. And whilst future learning landscapes will be characterised by the greater penetration of the Web within our everyday lives, fundamentally we must remember that we will still be, mostly, people socially interacting with other people. And this interaction will, in turn, be supported primarily through new dialogue and discourse. So this article argues for greater attention upon, and the pedagogical shaping of, the learning dialogue process within networked learning spaces through adopting contemporary approaches to learning design (e.g., Ravenscroft \& Boyle, 2010; Ravenscroft et al., 2011). And I argue that without a reworking of attested dialogue theory into 
more open and ambient pedagogies we will be less successful in converting mega-social interaction into mega-meaning making and learning. But perhaps the main point, or question, is even more fundamental and profound as whilst we pursue new forms of meaning making and communicative practice in the digital domain, through embracing the exciting possibilities offered by emerging web technologies, shouldn't our endeavours still fully appreciate the role of language and dialogue as our oldest and arguably still most powerful semiotic system?

"In the beginning was the word ..."- John 1:1.

\section{Acknowledgements}

The author is grateful to Gráinne Conole for our discussions of some of the ideas in this paper and also to all members of the Digital Dialogue Game (www.interloc.org.uk) and EC MATURE project (www.mature-ip.eu) teams who have developed the technologies or assisted with the ideas that are in this artic 


\section{References}

Attwell, G. (2007). Personal learning environments - the future of eLearning? eLearning papers, 2(1). Retrieved from http://www.elearningpapers.eu/index.php?

Bakhtin, M. (1986). Speech genres and other late essays. Austin: University of Texas Press.

Bjork, A. (2001). Tutorial learning for the new century. Journal of Science Education and Technology, 10(1), 57-71.

Downes, S. (2006). Learning networks and connective knowledge. Retrieved from http://it.coe.uga.edu/itforum/paper92/paper92.html

Friere, P. (2001). Pedagogy of freedom - ethics, democracy and civic courage. Lanham, MD: Rowman and Littlefield

Hegel, G. W. F. (1975). The logic of Hegel (W. Wallace, Trans.). Oxford: Clarendon Press.

Herring, S. (1999). Interactional coherence in CMC. Journal of Computer Mediated Communication, 4(4). Retrieved from http://jcmc.indiana.edu/vol4/issue4/herring.html

Kant, E. (1996). Critique of pure reason (Translation of original publication of 1781 by Werner, P.S.). Indianapolis/Cambridge: Hackett Publishing.

Levin, L. A., \& Moore, J. A. (1977). Dialogue-games: Metacommunication structures for natural language interaction. Cognitive Science, 1(4), 395-420.

Mackenzie, J. D. (1979). Question-begging in non-cumulative systems. Journal of Philosophical Logic, 8, 117-133.

McAlister, S., Ravenscroft, A., \& Scanlon, E. (2004). Combining interaction and context design to support collaborative argumentation using a tool for synchronous CMC. Journal of Computer Assisted Learning, 20(3), 194-204.

Mercer, N. (2000). Words and minds: How we use language to think together. London: Routledge.

Moore, D., Yuan, T., Reed, C., Ravenscroft, A., \& Maudat, N. (in press). Informal logic in human-computer dialogue. Knowledge Engineering Review, 26(3).

Ravenscroft, A. (2000). Designing argumentation for conceptual development. Computers \& Education, 34 (3-4), 241-255. 
Ravenscroft, A. (2004). From conditioning to learning communities: Implications of 50 years of research in eLearning interaction design. Association for Learning Technology Journal (ALT-J), 11(3), 4-18.

Ravenscroft, A. (2005). Towards highly communicative e-learning communities: Developing a socio-cultural framework for cognitive change. In R. Land \& S. Bayne (Eds.), Education in Cyberspace (pp. 130-145). London and New York: Routledge Falmer.

Ravenscroft, A. (2007). Promoting thinking and conceptual change with digital dialogue games. Journal of Computer Assisted Learning (JCAL), 23(6), 453-465.

Ravenscroft, A. (2009). Social software, web 2.0 and learning: Status and implications of an evolving paradigm. Journal of Computer Assisted Learning (JCAL), 21(1) 1-5.

Ravenscroft, A. \& Boyle, T. (2010). A dialogue and social software perspective deep learning design. Special Issue of Journal of Interactive Media in Education (JIME), Open University Computers and Learning Research Group (CALRG) 30 ${ }^{\text {th }}$ Anniversary. http://jime.open.ac.uk/article/2010-12/

Ravenscroft, A., Braun, S., \& Nelkner, T. (2010). Combining dialogue and semantics for learning and knowledge maturing: Developing collaborative understanding in the "Web 2.0 Workplace.” In Proceedings of International Conference on Advanced Learning Technologies (ICALT) 2010, July 5-7, 2010, Sousse, Tunisia.

Ravenscroft, A., \& Matheson, M. P. (2002). Developing and evaluating dialogue games for collaborative e-learning interaction. Journal of Computer Assisted Learning [Special Issue: Context, collaboration, computers and learning], 18(1), 93-102.

Ravenscroft, A., \& McAlister, S. (2006). Digital games and learning in cyberspace: A dialogical approach. E-Learning and Digital Media, 3(1), 37-50. Retrieved from http://www.wwwords.co.uk/elea/content/pdfs/3/issue3_1.asp\#5

Ravenscroft, A., McAlister, S., \& Sagar, M. (in press). Digital dialogue games and InterLoc: Deep learning design for collaborative argumentation on the web. In N. Pinkwart (Ed.), Educational technologies for teaching argumentation skills. Bentham Science E-Books. 
Ravenscroft, A. \& McAlister, S. (2008). Investigating and promoting educational argumentation: Towards new digital practices. International Journal of Research and Method in Education (IJRME): Special Edition on Researching argumentation in educational contexts: new methods, new directions, 31(3), 317-335.

Ravenscroft, A., \& Pilkington, R. M. (2000). Investigation by design: Developing dialogue models to support reasoning and conceptual change. International Journal of Artificial Intelligence in Education, 11(1), 273-298.

Ravenscroft, A., Sagar, M., Baur, E., \& Oriogun, P. (2009). Ambient pedagogies, meaningful learning and social software. In S. Hatzipanagos \& S. Warburton (Eds.), Social Software \& Developing Community Ontologies (pp. 415-433). Hershey, PA: IGI Global Publishing.

Ravenscroft, A., Schmidt, A., Cook, J. \& Bradley, (2011). Designing socio-technical systems for informal learning and knowledge maturing in the 'Web 2.0 workplace'. Article for Special Issue of Journal of Computer Assisted Learning (JCAL), on Designing and Evaluating Social Media for Learning, (Eds.) Ravenscroft, Warburton, Hatzipanigos \& Conole (due Summer 2011) (Submitted)

Ravenscroft, A., Wegerif, R. B., \& Hartley, J. R. (2007). Reclaiming thinking: Dialectic, dialogic and learning in the digital age. In J. Underwood \& J. Dockrell (Eds.), Learning through Digital Technologies (39-57). British Journal of Educational Psychology Monograph Series, 2(5).

Scardamalia, M., \& Bereiter, C. (2003). Knowledge building. In J. W. Guthrie (Ed.), Encyclopedia of education (2nd ed.). New York: Macmillan Reference, USA.

Searle, J. R. (1969). Speech acts: An essay in the philosophy of language. Cambridge, UK: Cambridge University Press.

Siemens, G. (2005). Connectivism: A learning theory for a digital age. International Journal of Instructional Technology and Distance Learning, 2(1), 3-10.

Siemens, G. (2006). Connectivism: Learning Theory or Pastime of the Self-Amused? [elearnspace blog]. Retrieved from http://www.elearnspace.org/Articles/connectivism_self-amused.htm

Verhagen, P. (2006). Connectivism: A new learning theory? Retrieved from http://elearning.surf.nl/e-learning/english/3793

Vygotsky, L. (1978). Mind and society: The development of higher psychological processes. Cambridge, MA: Harvard University Press. 
Walton, D. N. (1984). Logical dialogue games and fallacies. Lanham, MD: University Press of America.

Wegerif, R. B. (2007). Dialogic, education and technology: Expanding the space of learning. New York: Springer-Verlag.

Wegerif, R., Mercer, N., \& Dawes, L. (1999). From social interaction to individual reasoning: An empirical investigation of a possible socio-cultural model of cognitive development. Learning and Instruction, 9(5), 493-516.

Wertsch, J. V. (1991). Voices of the mind: A sociocultural approach to mediated action. Cambridge, MA: Harvard University Press.

Wittgenstein, L. (1953). Philosophical investigations (G. E. M. Anscombe, Trans.). Oxford, UK: Blackwell.

\section{Athabasca University $\mathbf{I}$}

